\title{
Possibilities of Functional Stupidity in Leading Schools during the COVID-19 Pandemic: A Case for Pandemic Leadership
}

\section{Sadi Mokhaneli Seyama \\ ORCID iD: https://orcid.org/0000-0002-5234-0555}

\section{Abstract}

The coronavirus disease 2019 (COVID-19) pandemic unexpectedly brought the world to its knees, creating health, economic, social and education crises. As a crisis, COVID-19 is characterised by uncertainties, anxieties, tensions and contradictions, requiring a strong leadership presence in its response. Consequently, people look up to leadership for answers, comfort, support and guidance in protecting people's lives. However, drawing from critical leadership studies, this paper contends that the demand for leadership during crises risks encouraging leadership romanticism, thus sanctioning leadership power, which could cause more harm than good. Despite the justifiable need for leadership's visibility and action during crises, there remains a risk of followers' unquestioned reliance on the leader, thus slipping into functional stupidity with devastating consequences.

The COVID-19 pandemic is causing a global education crisis, which is rendered more complex in education systems such as in South Africa which was already struggling with leadership legitimacy regarding its ability to provide equitable quality education and prepare learners for future work, prior to the pandemic. Thus, in this conceptual paper, pandemic leadership is proposed as a framework for responding to the COVID-19 pandemic and to future pandemics, while simultaneously mediating against repressive and silencing power and functional stupidity. Pandemic leadership offers significant leadership practices that centralise expert knowledge and related flexibilities; acknowledge the significance of the pandemic; deliberate on decisions while being considerate of contextual conditions; mobilise alternative voices and collaboration; demonstrate compassion and provide timely, valid, honest and transparent communication that builds trust. 
Keywords: COVID-19, crisis, critical leadership, functional stupidity, pandemic leadership, school leadership

\section{Introduction}

The coronavirus disease 2019 (COVID-19) pandemic unexpectedly brought the world to its knees, creating health, economic, social and education crises. The 'business' of life has changed drastically, requiring the world to take a deep breath, think and decide on a new course of life in view of both the short-term and long-term impact of COVID-19. According to the United Nations Educational, Scientific and Cultural Organization (UNESCO), the pandemic created the biggest ever shock in education where 1.6 billion young people have had their contact schooling suspended (UNESCO 2020). In South Africa, over 13 million learners attending school in almost 25000 schools have been affected (Department of Basic Education (DBE) 2020).

Following the lockdown, teaching and learning have been rearranged, revised and re-directed from being a teacher-driven process to a primarily learner-parent, technology-supported online process (Harris 2020). Depending on a priori school contexts and conditions, in this reorganisation of teaching and learning, some learners' progress in learning has been minimally affected, while for others, learning came to a standstill. Being in the COVID-19 crisis together does not mean schools are affected equally. Those who were already bearing the brunt of inequality and poverty have been more seriously affected by it than others (Ramrathan 2020); such cases require different school leadership responses during the crisis. School leaders have been confronted by the novel dilemma of how to protect stakeholders' lives, while at the same time guiding and supporting school learning to save the academic year. Consequently, school leadership is a focus of attention and critical surveillance.

In analysing school leadership, we have to recognise that COVID19 has exposed the global leadership crisis that has allowed the world and its people to be blind-sided by COVID-19 and to be exposed to potentially fatal risk. It must be pointed out that such leadership influences all leadership, both in the private and public sectors, including corporate leadership, health leadership and education leadership. An awareness of the influence of global leadership helps people to be realistic about the context within which local 
leadership, particularly local education leadership, has had to respond to COVID-19. Global leadership is failing to create a harmonious world where all people are given equal opportunities to flourish and live meaningful lives. The world is at war. There is increasing nationalism, leadership populism and post-truth claims, inequality, poverty and racism (Ladkin 2020). In this context, the problem of leadership is the destructive use of leader power, power that is self-serving, controlling and undermining people's agency, by world leaders such as the ex-President of the United States of America (USA) Donald Trump, Prime Minister of the United Kingdom (UK) Boris Johnson, the Indian Prime Minister Narendra Modi and Brazilian President, Jaid Bolsanaro (Collinson 2020). As Tourish (2020: 1) correctly points out, the COVID-19 pandemic is 'a crisis of leadership practice', which demands that we ask, 'How are key decision-makers performing, and what leadership systems, relationships and dynamics are producing good and bad results?'

COVID-19 is characterised by uncertainties, anxieties, tensions and contradictions that require leadership presence (O'Reilly et al. 2015). Consequently, people look up to leadership for answers, comfort, encouragement, support and guidance (Mabey \& Morrell 2011). However, drawing from critical leadership studies (CLS), this paper contends that the demand for leadership during crises risks leadership romanticism (Meindl et al. 1985), which creates and celebrates heroic leaders with absolute power and the supposed 'knowledge' to save the people. Crises sanction excessive leadership power - be it legitimate, charismatic or coercive power, which can cause more harm than good. Elevated in their positional power and taking up the responsibility to calm and reassure followers, leaders can appeal to excessive positivity or populism (Collinson 2020; Tourish 2020). Importantly, Grint (2020) is of the view that in a crisis, people often feel helpless and long for a 'knight in shining armour', a charismatic or authoritarian leader, who will destroy the threat, in this case, the novel coronavirus.

In view of critical leadership exposing the dark and destructive side of leadership, we cannot take for granted the increased decision-making power of leaders. While leadership's strong presence and response are vital during crises, we should be cautious of the likelihood of followers' passive acceptance of leaders' decisions, thus slipping into functional stupidity, which could prove futile in mediating crises effects. When leadership is centralised as it is the case during crises, there is a risk that followers will unthinkingly accept leaders' possibly unjustifiable decisions, fail to reflect 
on problematic assumptions and abdicate their responsibilities in the process.

This paper aims to provide conceptual tools for analysing school leadership during the COVID-19 and future crises. As a conceptual paper, it does not intend to provide empirical insights into how school leadership responded to COVID-19. Rather, the paper serves the dual purpose of warning about negative leadership in schools, that is, destructive leadership, and providing a tool to identify constructive leadership in schools during crises, that is, pandemic leadership. In warning about negative or bad leadership, the paper draws on Alvesson and Spicer's (2012a) 'functional stupidity' to illuminate the risk of followers looking up to leaders who, during crises, exploit that dependence on them for self-serving and destructive purposes. And in identifying positive or good leadership, Wilson (2020), drawing on the tradition of CLS conceptualises the "pandemic leadership' framework, which offers a guide for positive leadership in responding to COVID-19 and to any future crises.

To achieve its aim, the paper unfolds as follows. First, it offers a brief analysis of school leadership and the COVID-19 crisis' challenges. Second, it engages with the meaning of crisis and its influence on leadership. Third, it considers critical leadership as a useful framework for an alternative way of thinking, which critiques mainstream leadership studies' taken-forgranted assumptions that underlie the exercise of 'good leadership'. Fourth, the paper presents functional stupidity as an analytical tool to illuminate the dangers of romanticised leadership, thus enabling the framing of 'Positive Destructive Leadership' (PDL). To conclude, the paper outlines Wilson's (2020) pandemic leadership framework and then re-articulates it in terms of what it would mean for school leadership to adopt it in responding to the COVID-19 pandemic and any future crises.

\section{School Leadership and the COVID-19 Pandemic}

The COVID-19 pandemic has thrust school leadership into the worst crisis it has had to face in modern times. As a respiratory disease, COVID-19 is caused by a novel coronavirus that was discovered in Wuhan, China, late in 2019 (World Health Organization (WHO) 2020). By early January 2020, the world was already facing a global pandemic, which placed people's lives and livelihoods at risk (WHO 2020). The highly infectious nature of COVID-19 
requires social distancing to minimise infections, hence, governments implemented lockdown regulations. The South African President announced countrywide alert level 5 lockdown measures on 15th March 2020. Following that, the DBE (2020) released a statement announcing the closure of schools from 18th March 2020 to 14th April 2020, declaring that:

Provincial Education Departments, districts and schools are advised to take advantage of this time and are encouraged to utilise the time effectively by ensuring that learners participate in established stimulating programmes such as the Read to Lead programme, maths buddies, constructive holiday assignments, etc., through the supervision and guidance of parents and the broader community whilst learners are at home. This will be supported through the provisioning of workbooks, worksheets, readers, etc.

Cognisant of the South African school context, the short period within which schools had to prepare for the lockdown was a portent of looming disaster for the majority of schools. For many decades, school leadership has been characterised by crises (Jansen 2020), however, the COVID-19 crisis is different (Orem 2020). While struggling with inadequate resources and problematic stakeholder behaviour, school leadership has been confronted by an unending deluge of demands emanating from the complexities emerging from the world politics, neoliberal global economy and transforming societies. The advent of the COVID-19 pandemic is thus adding to school leadership's proverbially full plate of troubles.

In South Africa, COVID-19 could have devastating consequences for learning for many years to come, particularly when such learning has already been of a questionable quality (Soudien 2020). The COVID-19 pandemic exposed and further exacerbated learners' inequalities, which reflect society's economic divisions. Millions of learners attend public schools, which offer varying degrees of resources and levels of quality in education. For the advantaged schools, moving to on-line learning was achievable, while for the disadvantaged ones, learning was interrupted for the duration of the lockdowns (Davids 2020). Those learners from disadvantaged schools are at risk of losing learning that would set them up for failure in the future (Soudien 2020). Understanding the context of poor schools, Jansen (2020) questioned the DBE's initial illogical expectation for 
school leaders to provide online home-based learning. Most poor schools are yet to start with the digitisation of teaching and learning and there are very limited mobile devices such as smartphones, laptops or tablets that learners and teachers can use to achieve some semblance of learning during the lockdown.

COVID-19 has removed school routines, which promise consistency, predictable outcomes and a sense of flowing permanence and assurance. The bearings that have always provided school leaders with guidance have been lost. In many ways, school leaders have had to re-think and re-build their constructions and practices of leadership. School leaders have to balance regular, open and honest communication with shielding learners, educators and parents from unnecessary anxiety. Expectations are high for school leaders to facilitate a return to schooling that allows teaching and learning to progress, while simultaneously ensuring that lives are protected (Harris \& Jones 2020). The COVID-19 pandemic crisis means that school leaders have to work in a continuously changing context, where there are no concrete solutions to problems, yet 'to meet the immediate needs of students, families, teachers and staff, they must also plan for what may stretch into weeks or even months of school disruptions' (Starr 2020: 60). In essence, school leaders are expected to minimise interrupted learning and provide direction on how best to re-engage with learning both effectively and meaningfully. Finding appropriate answers in the dark, with absent or very limited reference points, is a momentous task, which puts school leadership under immense stress.

In South Africa, the task of leading schools during and following the lockdown has been a tall order for many school leaders, particularly those in poorer communities. This challenge has been exacerbated by poor national, provincial and district education leadership, which has not provided realistic and reliable communication and guidance. The indecisiveness surrounding the decision to re-open schools created more confusion and anxiety for learners, teachers and school leaders (Jansen 2020). The changing dates undermined school leaders' ability to take preparatory action in good time. Thus, the decisions on how to re-engage with face-to-face teaching and learning have not been easy. It has been a long process, characterised by varying and contradictory perspectives. School leaders have had to be mindful of the immediate effects of the pandemic on education, while still being unsure of the long-term impact (Harris 2020). To date, school leaders 
have implemented the DBE's school re-opening regulations, in particular sanitisation and social distancing as well as having smaller classes. There have been varying degrees of success and there have also been many challenges (Davids 2020). Observations point to inadequate resources, teacher exhaustion, teacher absenteeism, learner anxiety, district officials' autocratic approach, principals' lack of compassion, lack of parental support, to name but a few of the challenges (Jansen 2020). This gloomy picture highlights the need to interrogate school leadership in these challenging times. The next section engages with the meaning of crisis and its influence on leadership, which is needed to contextualise the framing of problematic and meaningful school leadership during the COVID-19 pandemic.

\section{Crisis and Leadership}

A crisis is an event that is urgent, causing uneasiness and warns of the possibility of harm (Kovoor-Misra 2019). It can surface unexpectedly, disrupting the status quo (O'Reilly et al. 2015). With the potential to cause chaos, a crisis can confuse organisational functioning, services and outcomes (Boin et al. 2018). Moreover, it can unsettle the bases on which an organisation derives its sense of purpose and mission. For example, during an earthquake or its aftershocks, people's sense of adequacy and control shifts, hence they look to leaders for solutions (Mabey \& Morrell 2011). Tomkins (2020: 3) observes that leaders' 'duty of care is intensified in times of crisis and that this involves not only showing up but also absorbing and enduring the distress and hostility they encounter, without deflecting, judging or retaliating'.

The instability that emanates from a crisis demands radical change to 'resolve' it (Dalcher 2020). As Boin et al. (2018: 24) point out, 'speaking of a crisis is in an odd way deeply optimistic: it suggests that the threat in question may still be averted if people, communities, institutions, leaders or systems rise to the challenge'. In this regard, appropriate mechanisms can be put in place to prevent further harm and to devise strategies for recovery. Therefore, crises explicitly demand leadership power, and its enactment is justifiable (Tomkins 2020). It is generally assumed that such power would be exercised appropriately to mediate against the detrimental effects of crises. However, from the functional stupidity and critical leadership perspectives, this is a time when organisations and people can be vulnerable 
to the misuse of leadership power. This 'power-risk' is observed mainly in populist and authoritarian leadership practices (Tourish 2020; Grint 2020). In a crisis, some leaders can enforce futile one-dimensional leadership practices (O'Reilly et al. 2015), which fail to consider different crisis management strategies, thereby exacerbating risks to people's lives in a pandemic such as COVID-19. It appears, therefore, that Mabey and Morrell's (2011) question will remain relevant in analysing leadership enactment during a crisis, 'what leadership is produced in times of crisis?' In this context, the lens through which this question is asked or answered is of paramount significance. The starting point is an acknowledgement that a crisis has exposed leadership's inadequacies and that from a crisis, new problems emerge. Therefore, new leadership approaches should discard traditional approaches (Dalcher 2020).

There is little doubt that leaders are highly challenged during a crisis. A crisis presents a very difficult time for them. Their responses, whether action or inaction, can determine the life or death of people or organisations (Boin et al. 2013). For some leaders, a crisis gives them a chance to restore followers' trust in them (Boin et al. 2013). For others, a crisis exposes their inefficiency (Dalcher 2020). In times of crisis, leaders can make decisions that lead to chaos (Friedman 2017). Depending on the leader's personality, leadership approach, experience, competencies, intellectual and emotional intelligence and the choice of power bases and tactics, a crisis can overwhelm some leaders. This can lead to inadequate or misguided decisions and actions. Simplistically, it is justifiable that leaders be held accountable for the success or failure of their performance in managing a crisis (Tomkins 2020). However, Boin et al. (2013: 81) offer a more realistic position, noting that:

There are many reasons that [why] we should not expect too much from crisis management. Consider how many factors affect the outcome of a crisis or disaster: the size, speed of onset, and 'knowability' or predictability of a threat agent determine how much leeway there is for crisis performance ....

Grint (2005: 1468) posits that '.. when a crisis occurs the successful leader must become decisive, demonstrate a ruthless ability to focus on the problem and to ignore the siren calls of the sceptics and the cynics'. Besides, leaders cannot afford to be narrow-minded and uncaring (Grint 2005). A crisis does 
not necessarily mean that all is doom and gloom. As Mabey and Morrell (2011: 106) correctly observe, 'it [a crisis] can expose the shortcomings of outmoded orthodoxy, paving the way for more radical, more 'in touch' ways of working'. For some organisations, a crisis can provide an opportunity to face the reality of their failures with the option of a total overhaul of the organisation (vision, purpose, structure, leadership, management, products, and services). For other organisations, a crisis may provide an opportunity for limited change (Kovoor-Misra 2019) or the right dose of momentum needed to implement a long-standing planned change.

Various leadership approaches are emerging during the COVID-19 era. On one hand, some are still grounded in the mainstream romanticism of leadership and leaders, with such leaders having a tendency to negatively exploit their newly granted power, thereby producing failing responses that further exacerbate the problems of COVID-19 (Collinson 2020; Ladkin 2020; Tourish 2020). On the other hand, there are those leadership approaches that are grounded in critical leadership paradigms that offer an observable effective and meaningful response to the COVID-19 pandemic (Wilson 2020). The next section considers critical leadership's perspectives as useful for an alternative approach to leadership thinking, which critiques mainstream leadership studies' taken-for-granted assumptions that underlie their pursuit of 'good leadership'.

\section{A Critical Leadership Studies' Perspective for School Leadership during a Crisis}

The critical leadership studies (CLS) project is committed to the interrogation of how leadership exploits power and politics in organisations. The CLS, emerging from critical management studies (CMS), which has taken the task of interrogating the problems of power and neoliberally informed management practices, aim to focus on problematic leadership (Alvesson $\&$ Spicer 2012b). Grounded in critical theory, CLS contend that mainstream leadership studies (MLS) have continued to seek effective leadership practices, that is, 'what works' and these often disregard nuanced contextual considerations in education spaces (Niesche \& Gowlett 2019). Consequently, MLS are somewhat blind to the increasingly harmful effects of neoliberally driven effective leadership practices. Inspired by the silence of MLS on the dangers and failures of asymmetric power in organisations, CLS 
recognise that leadership is complicit, indeed fundamental, in creating oppresssive organisations that engage in dehumanising leadership and management practices (Collinson 2011). Thus, CLS offer an alternative account of 'life' in organisations. In this sense, different lines of enquiry are engaged in, outside the attractive 'effective good leadership' on which MLS focuses.

Niesche and Gowlett (2019) argue that education leadership has fostered an unquestioned acceptance of the notions of 'efficiency' and 'effectiveness', which have been turned into powerful neoliberal tools. With the dominance of studies seeking effective leadership, that is, good leadership, there is primarily one face of leadership - a bright face - that is portrayed. Hence, justifiably so, we need insight into the other negative face of leadership - the dark face. In this sense, CLS close this gap, offering the possibility of an authentic holistic perspective to understand the complex, multi-dimensional aspects of leadership.

Critical leadership studies often reject heroic leadership perspectives that attribute organisational success to formal leaders only, without acknowledging the role of followers (Collinson 2011; Meindl et al. 1985). Consequently, they problematise centralised leadership and most importantly, the taken-for-granted assumptions that leadership is primarily 'good in itself' (Wilson 2014). Mabey and Morell (2011: 107) similarly contend that '.. heroic leadership theories, which are said to neglect context, reproduce normative control, overplay agency and fixate upon individual qualities, especially those which allow situations to be more effectively supervised and evaluated'. Furthermore, CLS warn about the dark side of leadership, which often leads to educational institutions' poor performance and the exploitation, bullying and marginalisation of educators (Niesche \& Gowlett 2019). Significant is the subjectification effect on educators, managers, leaders and learners. The CLS argue that leaders use their power to oppress dissenting views concerning an organisation's dominant thinking and culture (Alvesson \& Spicer 2012b).

In the context of this paper, a CLS lens enables an analysis of dangerous and ineffective leadership practices during crises as well as the advancement of meaningful and positive leadership practices. That is, a CLS perspective can expose the dark side of leadership and do something about it. It is possible to do this by adopting a moderate CMS stance, that is, critical performativity. Critical performativity transcends the critique of mainstream leadership thinking and practice to provide alternative practices that can 
undermine problematic mainstream practices and construct ideal emancipatory change (Spicer et al. 2009). Indeed, the literature on crises demonstrates that such leadership has prevented many possible disastrous pandemic situations. Critical performativity is supportive of present and active leadership during crises. What matters is how such leadership manages to respond appropriately to the crisis and protect people's lives and their livelihoods (Tourish 2020). Hence, in this paper, the consideration of pandemic leadership as a framework for positive leadership is advanced.

It is acknowledged that amidst the havoc that COVID-19 has created, opportunities to seek different ways of leading that align with the new normal of continuing-pandemic life have opened up (Dalcher 2020). Thus, this paper argues that a critical leadership perspective provides such an opportunity towards framing a different leadership that centres on humanity and harmonious meaningful life. The following section presents functional stupidity as an analytical tool to illuminate the dangers of leadership during crises, thus enabling the framing of 'Positive Destructive Leadership' (PDL) for school leadership.

\section{Functional Stupidity in School Leadership}

Against the dominant positivist rhetoric of leadership effectiveness, critical organisation studies point out the potential paradox of mainstream leadership thinking, where the pursuit of such leadership effectiveness can become the source of organisational failure when operationalised within a flawed or problematic knowledge frame. In opposition to the assumption of the rationality of organisational knowledge, the notion of functional stupidity was conceptualised as a critical tool to deepen insights into poor organisation thinking and practice (Alvesson \& Spicer 2012a). Alvesson and Spicer (2012a) propose the stupidity-based theory of functional stupidity to question the assumption that organisation strategies and functions are primarily undergirded by the use of intelligence.

Functional stupidity signifies the failure to use the extant intellectual capacity in an organisation to carry out an organisation's functions such as decision-making, reviewing practice and developing policy and regulations, etc. Alvesson and Spicer (2012a) argue that there are organisation practices that refute such claims of the common use of intelligence. Instead, functional stupidity is widespread in organisations. There are many pockets in organi- 
sations where there is an 'absence of reflexivity, a refusal to use intellectual capacities in other than myopic ways, and avoidance of justifications' (Alvesson \& Spicer 2012a: 1194). Consciously or unconsciously, people choose not to think critically (Paulsen 2016). It is important to note that most people do possess adequate thinking or intellectual capacities to develop effective and satisfying organisations. Functional stupidity does not suggest or refer to people's biological cognitive limitations (Alvesson \& Spicer 2012a). However, what is troubling is how organisations assume that smart people always use their intelligence to engage with their work (Alvesson \& Spicer 2012a). This assumption prevents people in organisations from gaining insight into why some organisational practices are not effective or even fail. Knowledge of functional stupidity is therefore relevant in closing this epistemological gap.

As an analytical lens, functional stupidity clarifies organisational conditions under which educated, knowledgeable, intelligent people do not use these capabilities in functional or purposeful ways. Instead, they choose or default to comfortable, familiar ways of thinking (Paulsen 2016). For some organisations, this mode of thinking is preferable because it maintains stability. Interrogative engagement carries the risk of debunking longestablished and celebrated organisational practices. In this vein, Alvesson and Spicer (2012) posit that functional stupidity reduces opportunities for conflict, which promotes harmonious organisational life. Moreover, 'it can also motivate people, help them to cultivate their careers, and subordinate them to socially acceptable forms of management and leadership' (Alvesson \& Spicer 2012a: 1197). However, from a critical position, functional stupidity leads to lessened critical agency, conformity, submission and avoidance of organisational punishment. It keeps the peace.

Essentially, functional stupidity fosters positivity in organisations, shielding people from the fear of negative outcomes. A functional stupidity lens exposes the problematics of excessively positive leadership approaches, such as Populist and Prozac leadership. It keeps us alert to the risks associated with romanticised leadership, which lures followers into uncritical followership (Ladkin 2020; Wilson 2014). The need for leadership during crises does not mean that people have to be pushed into subordinated positions; instead, it is a time when leaders should master the art of inspiring collaboration, see opportunities for leading from the back and empower others to take the leadership baton. 
A functional stupidity lens helps us to inquire into the negligent and fruitless pursuits that risk people's lives and, in the case of schools, undermine teachers' efforts to continue with the academic year. This is more relevant, where leadership exercises its power to remind others of their subordinate positions. Consequently, followers often engage in stupidity management and choose to avoid critical evaluation of organisational decisions and practices to escape the wrath of power. And, in times of crisis, when the propensity for failure is high, employees happily acknowledge their subordinated positions and promote discourses of heroic leadership and the related accountabilities. Similarly, seduced by leaders' positive rhetoric, followers opt for positive thinking amidst irrationality, avoid negative narratives and choose hopeful narratives (Collinson 2020; Ladkin 2020). To further untangle the usefulness of functional stupidity, the next section engages with how this lens can assist in the framing of Positive Destructive Leadership.

\subsection{Functional Stupidity and Positively Destructive Leadership}

This section offers the construction of Positive Destructive Leadership, which denotes a leadership that is grounded in excessive positivity in leadership enactment, producing functional stupidity outcomes. In the light of a functional stupidity analysis of leadership possibilities during a crisis, that is, the elevation of leadership's power during crises or that leadership is part of the crisis (O'Reilly et al. 2015); this paper recognises the paradox of positive power becoming negative power. By interrogating how leadership decisions and practices can foster functional stupidity, the paper draws on populist leadership (Tourish 2020; Schneiker 2020) and prozac leadership (Collinson 2012), which are grounded in excessive positivity about their leadership influence. The argument is that while it is indisputable that positivity is one of the most important dimensions of leadership, excessive positivity can be futile in fostering meaningful and effective leadership during crises (Collinson 2012). It can produce self-defeating tendencies and outcomes with damaging effects. This paper constructs positive destructive leadership during crises by re-articulating populist and prozac leadership approaches. Essentially, Positive Destructive Leadership typifies the dark side of leadership and it is significant in identifying leadership approaches 
that leaders should avoid if they are committed to ensuring a meaningful and effective response to a crisis like the COVID-19 pandemic. Most importantly, it raises followers' awareness of the dangers of leaders' excessive positivity during crises.

\subsubsection{Populist Leadership}

As noted in the introductory section, the recent and current global political leadership (Trump, Johnson, Bolsanaro) can influence how other leadership, such as education leadership, is responding to the COVID-19 pandemic. It is within this context that this paper considers the possible influence of populist leadership on school leadership, with some distinct dynamics. Populist leadership is a form of political leadership that is characterised by leaders who position themselves as anti-elitist, anti-pluralist and as standing with the people in opposing the political establishment and elites who undermine ordinary people's interests (Moffitt 2016). They exploit their political power to convey a positive message of dismantling oppressive legislation and policies (Weyland 2001). Populist leaders not only drive the populism ideology, but they also engage in specific political performances (Moffitt 2016) that have characterised populist leadership. These performances serve to build a trusting and hero-worship relationship with followers (Ladkin 2020). As Schneiker (2020: 857) points out, they become the superheroes, the 'saviours in times of crisis'.

From an organisational behaviour perspective, politics are pervasive in organisations and are often perceived negatively because the political system is the means through which power is exploited. Hall et al. (2004) concede that political behaviour creates tension and conflict in organisations, which undermine people's positive engagement with their job. In highly political organisations, people often minimise their job engagement because they do not believe their efforts will be fairly recognised and rewarded (Hall et al. 2004). This paper recognises that amid organisational political plays, there are leaders who adopt populist approaches to drive their self-aggrandisement agendas. In organisations, leaders talk and act like populists to entice their followers to buy into their ideas and to support their plans to advance selfserving organisational policies or to gain the top positions. Therefore, the paper contends that a populist leadership perspective is necessary and relevant in educational contexts where politics manifests itself in different forms. 
During crises, populist leaders are highly energised and appear in control. However, their actions are often deceiving. They are mostly not competent to solve crisis-related complexities (Tourish 2020). In a crisis, populist leaders feel obliged in their superhero guise to carry positive messages to followers. They cannot afford to communicate doom and gloom, lest it costs them followers. Thus, they present a false reality (Grint 2020), hiding the depth of the problem or the looming danger. Furthermore, populist leaders, in their need to appease, fail to command requisite compliance in a crisis. As a result, they hesitate to make tough, unpopular decisions, which can put lives at risk. Additionally, they have a tolerance for mediocrity. They settle for superficial solutions because they cannot urge people to put more effort into effective and sustainable solutions (Moffitt 2016). Populists sacrifice meaningful practices or people because they do not serve their interests, people with the agency to provide alternatives or with the courage to expose problematic decisions. Populist leaders undermine ethics and open doors for corruption, incompetence and the slackening of regulations (Friedman 2017). They are denialists and when caught in their lies or halftruths, claim fake news, shifting the responsibility to other people (Friedman 2017). They tend to discount scientific or empirical evidence and support common sense, which they ground on a one-dimensional approach, marginalising other perspectives (Mudde 2004; Tourish 2020). However, all this exposes their disingenuous intent, inadequate knowledge and incompetence.

In crises, populists fail to create a common vision because they foment conflict between the people and the elites (Mudde 2004). However, they are not aware of this weakness as they thrive on conflict. This results in the absence of a collaborative team spirit, a sense of solidarity, which is important to overcome a crisis. There is no compassion, support and care. Fearing failure, populist leaders' default to autocratic leadership when their demands are not met (Dalcher 2020).

\subsubsection{Prozac Leadership}

Collinson (2012) advanced the notion of Prozac leadership to illuminate the risks associated with the excessive positivity of leadership and to interrogate the normative assumptions underlying leadership positivity's currency as an effective leadership approach. Prozac is a prescribed anti-depressant, which assists with emotional upliftment, to give a sense of happiness and positivity 
(Collinson 2012). Collinson (2012: 89) drew on this metaphor to demonstrate the high levels of 'social addiction to excessive positivity', which leaders exploit to gain followership. Of concern is how such an obsession can limit people's ability to question such leaders' thinking and actions. Prozac leaders create an overly optimistic persona, which carries a 'happy' message that all is in order, that they are in control of the situation and that there are no problems (Collinson 2012). However, 'followers feel obligated to keep up the good message and, as such, avoid reporting problems, which leaves societies and organisations ill-prepared to deal with unexpected events and threats' (Collinson 2020: 2). Prozac leadership represents the temporality of light in persistent darkness. Prozac leaders are shining stars in moonless nights and offer hope in a hopeless world. So how could they bring disaster? Collinson (2012: 94) warns that prozac leaders' 'bright siding can leave organisations "blindsided", failing to prepare adequately for a crisis. Promises of solutions are not kept, revealing the paradox that a positive message can become a toxic message'.

In the light of leadership needs in a crisis, it is apparent from the analysis of populist and prozac leadership that they can produce positive destructive leadership, including in school contexts. They signify functional stupidity because excessive positivity produces a belief in its own empty and toxic messages, with disastrous consequences. Similarly, populist and prozac leadership approaches create conditions under which followers consciously or subconsciously slip into functional stupidity. Subconsciously, the seduction of the superhero undermines followers' critical thinking. They fail to use their intellect to question irrational, inconsistent or contradictory messages or even seek justifications for leaders' actions. From a conscious perspective, followers are forced to silence their voices. Therefore, they cannot speak truth to power and 'choose' to carry out leaders' instructions or perform job tasks that are patently ineffective or even detrimental to an organisation.

\section{Implications of Positively Destructive Leadership for School Leadership in Response to the COVID-19 Pandemic}

How would school leadership respond to COVID-19 if it were guided by 
positive destructive leadership? Without question, in light of the COVID-19 crisis, positive destructive leadership would manifest in disastrous school leadership behaviour. Such school leaders would not be in a position to demonstrate the requisite pragmatic and affective competencies needed to minimise COVID-19 infection risks and to save the academic year. The following could typify school leaders' shortcomings:

1. Failure to communicate a common vision. This would provide the premise from which all stakeholders could gain an understanding of the pandemic and get the appropriate direction and inspiration to work together to respond to the crisis. A typical laissez-faire attitude towards the dangers of COVID-19 would result in school leaders failing to provide adequate or appropriate planning and organisation for responding to COVID-19.

2. Failure to deliver a correct scientific message about the danger of the virus. This could encourage learners, teachers and parents to adopt risky behaviours such as reluctance to take appropriate sanitisation care and not following social distancing practices. In such a situation, school leaders would fail to use their authority to enforce safety regulations, creating a false sense of security. In their ignorance of the dangers, leaders could be reluctant and unwilling to allocate resources to develop effective crisis management preparedness plans for learners, educators and staff.

3. Engagement in poor communication strategies. This could include inconsistent and contradictory messages, causing confusion. School leaders could also provide non-transparent communication that undermines trust. They could misuse meetings for self-promotion, meaningless pep talks or rants about those who undermine their leadership.

4. Exhibiting limited contextual insights. This refers to an inability to develop a holistic understanding of various aspects of COVID-19 and its influence on a school's operation. School leaders could then allocate resources inappropriately or take isolated actions that provide temporary solutions, which would serve only to deepen the problems. 
5. Lack of reflexivity. With a strong belief in their knowledge, leaders would not question their assumptions. That would promote superficial reflection and analysis and limited attention to detail. Yet, they would still expect miraculous outcomes.

6. Engage in authoritarian leadership to enforce one-dimensional perspectives. This stifles creativity. School leaders could exploit their authority to enforce practices that deviate from accepted, evidence-based scientific recommendations. They could use bullying tactics to isolate those who present an opposing view. In this way, they would create division and jeopardise collaboration, co-operation and mutual support.

7. Promote instrumentalist behaviour. This focuses on quantitative outcomes as opposed to qualitative outcomes; completing the curriculum, for instance, instead of providing learners with meaningful knowledge that would strengthen the foundation required for their next level of learning (Ramrathan 2020).

8. Keep up appearances to safeguard the good, impressive image of positivity and control. School leaders could attempt to protect their integrity by reporting false success, under-reporting damage or failure or even promoting people's ignorance of practices that do not work. They could force teachers to stretch themselves beyond their physical, mental and emotional capacities without seeking assistance for more material resources and personnel, for example, cleaning staff and temporary teachers. In an environment of 'positivity', people will fear to report health struggles in case they are seen to be weak or negative while pushing themselves to breaking point.

9. Failure to lead with compassion. In practising positive rhetoric, leaders could neglect to show compassion and care and instead take staff's stress for granted and continue to make unreasonable performance demands.

The next section outlines a pandemic framework for school leadership to adopt in responding to the COVID-19 pandemic and future crises. 


\section{A Pandemic Framework for School Leadership during the COVID-19 Pandemic}

Given the possibilities of functional stupidity, the epistemological and ontological stance of critical leadership studies, and the presented Positive Destructive Leadership, this section offers a pandemic leadership framework for school leadership. Wilson (2020) conceptualised the pandemic leadership framework following her observation and analysis of New Zealand's Prime Minister, Jacinda Arden who demonstrated exemplary leadership in saving people's lives and livelihoods early in the pandemic. It offers a political perspective of good leadership practices during a pandemic. The critical analysis revealed leadership practices that produced positive outcomes in response to COVID-19 induced crises. This managed to limit infection and mortality rates, with negligible damage to the economy. In view of the context of this conceptualisation, the paper re-articulates the pandemic leadership framework's usefulness in guiding school leadership's response to COVID-19.

In consideration of the dark side of leadership, particularly in times of crises when leaders feel justified to use their power to make decisions and use their public platforms for populist self-interests, the pandemic framework for school leadership offers a humane-centred approach that prioritises people's lives and needs above economic and political interests. Most importantly, it acknowledges the need for leadership, however, without fostering or faltering onto heroic leadership. As O-Reilly et al. (2015: 492) correctly point out, in crisis, we need '... leadership processes that are open, exploratory, mutual, questioning rather than directive, end-focussed, asymmetrical and based on the assumption of knowledge...'. It is in this line of thinking that a pandemic framework is proposed to respond to the COVID19 pandemic and future pandemics within the school context while mediating against repressive silencing power and functional stupidity. Wilson's (2020) pandemic leadership framework offers a leadership approach that is grounded in fostering a shared purpose and engaging in leadership practices that build trust in leadership. Consequently, the pandemic's good leadership practices encompass:

- Centralising Expertise Knowledge and Related Flexibilities As it is caused by the novel coronavirus, COVID-19 has presented 
knowledge gaps and uncertainties therefore scientific expertise is the main point of reference for guiding pandemic regulations (Tomkins 2020). It offers concrete evidence that leadership could use to build communities' trust in their decisions. Working outside such knowledge could pose unimaginable risk to people's lives and economies. Consequently, in managing the pandemic, leadership should place trust in expertise knowledge and allow it to guide decision-making (Wilson 2020). As experts continue to study the virus, new knowledge emerges, requiring leadership to take into consideration and amend regulations accordingly - swiftly and resolutely.

\section{- Mobilising the Collective Effort}

COVID-19 is a highly communicable disease, and it affects whole communities, transforming their lives. To control its virulence and pandemic consequences, collective efforts are indispensable. Within a pandemic leadership framework, leaders ought to rally communal commitment under the auspices of the shared purpose of saving lives and livelihoods (Wilson 2020). Collective efforts are built on trust; thus, a deliberate, transparent, credible leadership is required to get communities on board in taking responsibility to change behaviours and effectively manage the pandemic together (Grint 2020).

\section{- Enabling Coping during the Pandemic}

Under the threat of the pandemic with its unpredictability, pandemic leadership takes the responsibility of empowering communities to cope with the pandemic. Governments need communities to take the baton of fighting the spread of the virus, thus they have to provide the communities with the appropriate and current knowledge and competencies (Grint 2020). To do this, leadership has to provide clear, unambiguous, updated and expert based information about the virus and ensure that regulations are properly aligned. Furthermore, to enhance communities' ability to cope and protect their wellbeing, leadership should focus on a caring and considerate approach (Wilson 2020).

The framing guides meaningful leadership practices and at the same time, it can be used as a lens for interrogating school leadership in the times of pandemic crises in education or any context. The COVID-19 pandemic is a 
wicked problem with varying dimensions that encapsulate changing dynamics (Grint 2020). It thus demands consideration of variable leadership and management priorities all at the same time, which is a tall order in a highly pressurised environment. As Grint (2020) suggests, leaders have to interchangeably lead, manage and command to safeguard a meaningful COVID-19 pandemic response.

To minimise infections, save lives and economies, overall, school leadership requires strong organisational behaviour insights, notwithstanding pandemic-specific knowledge. These comprise appropriate power bases and tactics, strategic leadership, crisis management, change management, cognitive intelligence, emotional intelligence, workforce diversity dynamics, stress management and wellness. Ultimately, leaders should be soldiers on the ground. The following provides school leadership practices that guide a response to the COVID-19 pandemic:

\section{Create a Dominant Scientific Frame of the Existence and Significant Dangers of the Pandemic}

As a start, school leadership should deliberately filter through pandemic-affirming public discourses. It should use strategies to ensure the dominant message, which offers a clear, evidence-based interpretation of the crisis (Boin et al. 2013). For an effective response to a pandemic, people need a common understanding of the pandemic (Wilson 2020). Diverging perspectives could thwart efforts to foster a common vision and collective meaningful response. In a pandemic, leadership should then construct and manage the meaning people make of the crisis (Boin et al. 2013). Importantly, they are morally bound to construct a realistic lens through which people will view and interpret the pandemic. This determines their co-operation, embracement and compliance of regulations and the taking of appropriate safety measures. Furthermore, it helps to focus on real issues of the pandemic and reduces opportunities for the politicisation of the pandemic.

\section{Engage in Decisive Communication that Builds a Collective Response and Resilience}

To deliver purposeful COVID-19 pandemic messages that encourage compliance, school leadership should provide a measured communication that is based on scientific evidence to ensure its reliability. To 
build trust, communication should be transparent, honest and timely (Wilson 2020). Crucially, it ought to relate the true nature of the pandemic and associated risks, without causing debilitating alarm (Grint 2020). It should clarify why the virus is dangerous and outline possible measures to curb it (Boin et al. 2013). Additionally, there needs to be clarity on what can be done and what cannot be done and honesty about the school's capacity to minimise risks. The leadership's communication should send a message of a shared sense of school unity in fighting the pandemic. In this regard, school leaders are obliged to be brutally frank and hold people accountable for their share of responsibilities (Grint 2020).

\section{Undertake a Systematic Holistic Analysis and Critical Interpretation of the Pandemic Environment}

To take account of a school's needs, school leadership should undertake a systematic comprehensive examination of the macro (wider social, political, economic context) and micro (immediate school) context of the pandemic (Orem 2020). Such a holistic evaluation guides the development of an understanding of the 'big picture', with its dimensional nuances, the roles of each, and their influence on each other. This can enable school leadership to identify immediate and longterm needs and plan accordingly. Given that COVID-19 is a serious problem, school leadership needs to seek out varying perspectives from school stakeholders for an integrated and meaningful plan. Considerate of the many unknowns, leadership should take the approach of asking the right questions rather than providing concrete one-dimensional answers (O-Reilly et al. 2015). Furthermore, leadership ought to ask questions about 'potential disruptors' and develop strategies to mitigate against these (Orem 2020: 8). This reduces room for surprises in the middle of a crisis.

\section{Make Continuous, Critical and Deliberate Decisions}

Being considerate of crisis uncertainties, tensions, contradictions and evolving context, school leadership should adopt a dialectical approach to decision-making, which takes into account the holistic needs analysis. A consultative and collaborative decision-making process will enable open and honest deliberations. In this way, tensions and contradictions 
can be considered critically and with appropriate flexibility. As follows, leadership can enable adaptability and appropriate actions to align with any changes (Orem 2020). Of importance are decisions that are grounded on scientific evidence and are mindful of the nature of the school's capacity and available resources. This will guide decision-making even when the decisions are 'difficult and unpopular' (Grint 2020: 3).

\section{Foster and Support Learning}

A crisis is unexpected and often brings previously unencountered problems, thus school leadership needs to develop critical knowledge about the pandemic and continuously engage experts to keep abreast of new developments. The constantly changing and uncertain setting of the crisis demands school leadership's quick-thinking capacity to learn and make informed and eventually sustainable decisions (Boin et al. 2013). Leadership should start learning from similar experiences and take what has worked. Essentially, those leading schools require the capacity to steer schools into learning organisations and central to this is the opening of spaces for innovative problem-solving. In this transition, school leadership and stakeholders should engage in a critical reflection of earlier decisions and actions and crucially take learnings from these. To enhance learning, leadership should foster team learning through knowledge sharing and create networks for expert support to guide, share and implement effective, evidence-based methods (Harris 2020).

\section{Lead with Compassion}

Crises are traumatic and leaders are central to creating a coping space, thus caring about the suffering of others is a vital dynamic during a crisis (Tomkins 2020). In the time of the COVID-19 pandemic, the demand for school leadership's visibility extends beyond minimising COVID19 risks, to genuine care and kindness to stakeholders. Learners, educators and parents need school leaders to acknowledge their distress and be thoughtful about their traumatic experiences (Jansen 2020; Harris \& Jones 2020). For leaders, it is about going the extra mile, taking the time to ask how people are coping and providing the necessary support. Significant as well is how school leaders should recognise the pressures on educators and resist creating additional demands that fall outside the immediacy of the COVID-19 pandemic response. 


\section{Acknowledge Mistakes}

School leaders should accept the inherent accountability that leadership carries. As Tomkins (2020) notes, at some point a leader is celebrated and at another time criticised. It is recognised that the unknowns of a crisis increase possibilities for leadership mistakes. Taking accountability for their mistakes demonstrates leaders' maturity, honesty and the leaders gain their followers' respect and trust. Thus, school leaders can move on to find appropriate solutions and importantly, inspire educators and other staff to report mistakes and shortcomings.

\section{Start Building a Recovery Plan}

It is without a doubt that schools will operate and provide learning beyond the pandemic. However, what matters is how they recoup, use lessons learned and transform leadership for a more ready and resilient future. While confronted by the immediate needs of stakeholders, school leadership should start planning beyond the pandemic and capitalise on opportunities to build resilient schools (Starr 2020). To build a recovery plan, leadership should utilise available information (even if it is limited and uncertain about the future) to start making sense of the medium-term and long-term effects of the pandemic. To begin, leadership should undertake a critical reflection of the decisions and conditions that enabled or disabled its response to the pandemic. The focus should be on building school and stakeholders' readiness for crisis management as they build foundations for a future proactive response. As noted, crises create opportunities for change (Dalcher 2020), therefore school leadership should take advantage of the opportunities to rethink its leadership and management approaches and align these with 21 st-century paradigms that are centred on humanity, innovation and environmental consciousness. The rethinking of the curriculum is one important opportunity that Soudien (2020) and Ramrathan (2020) have highlighted in ensuring that quality learning takes place in classrooms. The digitisation of learning is the second imperative prospect that the pandemic has provided in the right dose of momentum needed to implement it. To accomplish all this, school leadership has to enable leaders across the whole school at different levels (Harris \& Jones 2020). 


\section{Conclusion}

This conceptual paper aimed to provide possible insights into what it would be like for school leadership to take up Positive Destructive Leadership and pandemic leadership approaches in response to the COVID-19 pandemic crisis. Drawing from the functional stupidity perspective and CLS, the paper demonstrates that leadership does not always produce inspiration for people to engage in effective and meaningful performances. Instead, in a crisis when leadership visibility is demanded, excessive leadership positivity, as enacted by populist and prozac leaders, can produce damaging outcomes. In a school context, Positive Destructive Leadership can cause confusion, conflict, defiance of safety regulations and lack of appropriate planning, thus producing meaningless and dangerous performance outcomes. Ultimately, learners, educators and parents' lives would be exposed to risk and efforts to save the integrity of the academic year would be undermined. In advancing the pandemic framework for school leadership during COVID-19, the paper provides guidelines that school leadership could follow in responding to COVID-19 or future pandemics. To further advance the case for CLS in educational contexts, empirical studies would be necessary to explore contextual conceptualisations of Positive Destructive Leadership and pandemic leadership approaches.

\section{Acknowledgements}

I thank Dr. Clive Smith for comments on previous drafts of this article.

\section{References}

Alvesson, M. \& A. Spicer 2012a. A Stupidity-Based Theory of the Organization. Journal of Management Studies 49,7: 1194 - 1220. Available at: https://doi.org/10.1111/j.1467-6486.2012.01072.x

(Accessed on 13 March 2017.)

Alvesson, M. \& A. Spicer 2012b. Critical Leadership Studies: The Case for Critical Performativity. Human Relations 65,3: 367 - 390. Available at: https://doi.org/10.1177/0018726711430555

(Accessed on 12 March 2016.)

Boin, A., S. Kuipers \& W. Overdijk 2013. Leadership in Times of Crisis: A 
Framework for Assessment. International Review of Public Administration 18,1: 79 - 91 .

https://openaccess.leidenuniv.nl/bitstream/handle/1887/29937/06Arjen

_Boin_Sanneke_Kuipers_\%26_Werner_Overdijk.pdf?sequence $=1$

(Accessed 06 on June 2020.)

https://doi.org/10.1080/12294659.2013.10805241

Boin, A., P. T'Hart \& S. Kuipers 2018. The Crisis Approach. In Rodríguez,

H., W. Donner \& J.E. Trainor (eds.): Handbook of Disaster Research.

Cham: Springer International Publishing.

https://doi.org/10.1007/978-3-319-63254-4_2

Collinson, D. 2011. Critical Leadership Studies. In Collinson, D., A. Bryman, K. Grint, B. Jackson \& M. Uhl-Bien (eds.): Handbook of Leadership Studies. Thousand Oaks, CA: Sage Publications. https://doi.org/10.4135/9781446262344

Collinson, D. 2012. Prozac Leadership and the Limits of Positive Thinking. Leadership 8,2: 87 - 107. Available at:

https://doi.org/10.1177/1742715011434738

(Accessed on 11 May 2019.)

Collinson, D. 2020. False Positives: A Pandemic of Prozac Leadership.

Available at: http://www.ila-net.org/Reflections/dcollinson.html

(Accessed on 15 October 2020.)

Dalcher, D. 2020. Leadership in Times of Crisis: What's Different Now? PM World Journal IX(V). Available at:

https://pmworldjournal.com/article/leadership-in-times-of-crisis (Accessed on 10 September 2020.)

Davids, N. 2020. Opinion: Maybe the Coronavirus will Set SA on a Path to a More Equitable Education System. Available at:

https://m.news24.com/Columnists/GuestColumn/opinion-maybe-the-

coronavirus-willset-south-africa-on-the-path-to-a-more-equitableeducation-system-20200327

(Accessed on 12 August 2020.)

Department of Basic Education (DBE), South Africa 2020. Containment/ Management of COVID-19 for Schools and School Communities.

Available at: https://www.nicd.ac.za/wp-

content/uploads/2020/11/Revised-DBE-guidelines-Management-of-

COVID-in-schools Sept2020.pdf

(Accessed on 13 August 2020.) 
Friedman, U. 2017. What is a Populist? And is Donal Trump One? Available at: https://www.theatlantic.com/international/archive/2017/02/what-ispopulist-trump/516525/ (Accessed on 13 September 2020.)

Grint, K. 2005. Problems, Problems, Problems: The Social Construction of 'Leadership'. Human Relations 58,11: 1467 - 1494. Available at: https://doi.org/10.1177/0018726705061314 (Accessed on 30 May 2020.) https://doi.org/10.1144/geosci-30-4

Grint, K. 2020. Leadership, Management and Command in the Time of the Coronavirus. Leadership 16,3: 314 - 319. Available at: https://doi.org/10.1177/1742715020922445

(Accessed on 30 May 2020.)

PMCid:PMC7201192

https://doi.org/10.1144/geosci-30-4

Harris, A. 2020. COVID-19 - School Leadership in Crisis? Journal of Professional Capital and Community. Available at:

https://www.emerald.com/insight/content/doi/10.1108/JPCC-06-20200045/full/pdf?title $=$ covid-19-school-leadership-in-crisis $\quad$ (Accessed on 28 July 2020.) https://doi.org/10.1108/JPCC-06-2020-0045

Harris, A. \& M. Jones 2020. COVID-19: School Leadership in Disruptive Times. School Leadership \& Management 40,4: 243 - 247. Available at:

https://www.tandfonline.com/doi/full/10.1080/13632434.2020.181147 $\underline{9}$ (Accessed on 28 July 2020.)

Hall, A., W. Hochwater, G. Ferris \& M. Bowen 2004. The Dark Side of Politics in Organizations. In Griffin, R. \& O'Leary-Kelly, A. (eds.): The Dark Side of Organizational Behavior. San Francisco: Jossey-Bass.

Jansen, J. 2020. Let's Face Facts, the 2020 School Year is Lost. So, What to Do? TimesLive. Available at: https://select.timeslive.co.za/ideas/202004-09-lets-face-facts-the-2020-school-year-is-lost-so-what-to-do/

(Accessed on 12 August 2020.)

Kovoor-Misra, S. 2019. Crisis Management: Resilience and Change. London: SAGE Publications.

https://doi.org/10.4135/9781506328676.

Ladkin, D. 2020. What Donald Trump's Response to COVID-19 Teaches Us: It's Time for Our Romance with Leaders to End. Leadership 16,3: 273 - 278. Available at: https://doi.org/10.1177/1742715020929134 (Accessed on 30 May 2020.) 
Mabey, C. \& K. Morrell 2011. Leadership in Crisis: 'Events, My Dear Boy, Events'. Leadership 7,2: 105 - 117. Available at:

https://journals.sagepub.com/doi/10.1177/1742715010394732

(Accessed on 30 May 2020.)

Meindl J., S. Ehrlich \& J. Dukerich 1985. The Romance of Leadership. Administrative Science Quarterly 30,1: 78 - 102. Available at:

https://www.jstor.org/stable/2392813?seq=1

(Accessed on 11 March 2018.) https://doi.org/10.2307/2392813

Moffitt, B. 2016. The Global Rise of Populism: Performance, Political Style, and Representation. Stanford, CA: Stanford University Presse.

https://doi.org/10.1515/9780804799331

Mudde, C. 2004. The Populist Zeitgeist. Government and Opposition 3,4:

541 - 563. Available at:

https://doi.org/10.1111/j.1477-7053.2004.00135

(Accessed on 28 July 2020.)

Niesche, R. \& C. Gowlett 2019. Why Use Social, Critical and Political Theories in Educational Leadership? In Niesche, R. \& C. Gowlett (eds.): Social, Critical and Political Theories for Educational Leadership. Singapore: Springer. https://doi.org/10.1007/978-981-13-8241-3

O'Reilly, D., C. Leitch, R. Harrison \& E. Lamprou 2015. Leadership, Authority and Crisis: Reflections and Future Directions. Leadership 11,4: 489 - 499. Available at:

https://journals.sagepub.com/doi/full/10.1177/1742715015596641

(Accessed on 20 June 2020.)

Orem, D. 2020. A Crisis at Our Door: Can We Prepare for a Black Swan

Event? Available at: https://www.nais.org/magazine/independentschool/summer-2020/on-my-mind-a-crisis-at-our-door/

(Accessed on 20 August 2020.)

Paulsen, R. 2016. Slipping into Functional Stupidity: The Bifocality of Organizational Compliance. Human Relations 70,2: 185 - 210.

Available at: https://doi.org/10.1177/0018726716649246

(Accessed 20 June 2020.)

Ramrathan, L. 2020. School Curriculum in South Africa in the COVID 19 context: An Opportunity for Education for Relevance. Prospects 53: 383 - 392. Available at: https://doi.org/10.1007/s11125-020-09490-1 (Accessed on 02 October 2020.)

PMid:32836431 PMCid:PMC7406695 
Schneiker, A. 2020. Populist Leadership: The Superhero Donald Trump as Savior in Times of Crisis. Political Studies 68,4: 857 - 874. Available at: https://doi.org/10.1177/0032321720916604

(Accessed on 13 September 2020.)

Soudien, C. 2020. Complexities of Difference and their Significance for Managing Inequality in Learning: Lessons from the COVID 19 Crisis. Prospects 49: 59 - 67. Available at: https://doi.org/10.1007/s11125020-09486-x (Accessed on 13 September 2020.)

PMid:32836428 PMCid:PMC7333787

Spicer A., M. Alvesson \& D. Kärreman 2009. Critical Performativity: The Unfinished Business of Critical Management Studies. Human Relations 62,4: 537 - 560. Available at:

https://doi.org/10.1177/0018726708101984

(Accessed on 20 March 2017.)

Starr, J. 2020. Responding to COVID-19: Short and Long-Term Challenges.

Phi Delta Kappan 101,8: 60 - 61. Available at:

https://doi.org/10.1177/0031721720923796

(Accessed on 20 August 2020.)

Tomkins, L. 2020. Where is Boris Johnson? When and Why it Matters that Leaders Show Up in a Crisis. Leadership 16,3: 331 - 342. Available at: https://doi.org/10.1177/1742715020919657

(Accessed on 30 May 2020.)

https://doi.org/10.1144/geosci-30-4

Tourish, D. 2020. Introduction to the Special Issue: Why the Coronavirus

Crisis is also a Crisis of Leadership. Leadership 16,3: $261-272$.

Available at: https://doi.org/10.1177/1742715020929242

(Accessed on 30 May 2020.)

United Nations Educational, Scientific and Cultural Organization (UNESCO) 2020. COVID-19 Response Website. Available at:

https://en.unesco.org/covid19/educationresponse

(Accessed on 01 August 2020.)

Weyland, K. 2001. Clarifying a Contested Concept: Populism in the Study of Latin American Politics. Comparative Politics 34: 1 - 22. Available at: https://doi.org/10.2307/422412

(Accessed on 13 September 2020.)

Wilson, S. 2014. The Maintenance of Leader-Centricity Via the Discursive Subjugation of the Follower. Conference Paper in Academy of 
Management Annual Meeting Proceedings. Available at: https://doi.org/10.5465/ambpp.2014.10918 (Accessed on 03 September 2017.)

Wilson, S. 2020. Pandemic Leadership: Lessons from New Zealand's Approach to COVID-19. Leadership 16,3: 279 - 293. Available at: https://doi.org/10.1177/1742715020929151 (Accessed on May 2020.) World Health Organization (WHO) 2020. Mission Summary: WHO Field Visit to Wuhan, China [Press release]. Available at:

www.who.int/china/news/detail/22-01-2020-field-visit-wuhan-chinajan-2020 (Accessed on 29 June 2020.)

Sadi Mokhaneli Seyama Senior Lecturer Education Leadership and Management University of Johannesburg Johannesburg sseyama@uj.ac.za 